\title{
MATERIALES ARQUEOLÓGICOS DEL CASTRO DE VIGO
}

\author{
JOSÉ MANUEL HIDALGO CUÑARRO \\ Departamento de Prehistoria y Arqueología \\ del Museo Municipal «Quiñones de León» de Vigo
}

\begin{abstract}
Se presentan las piezas más importantes encontradas hasta la actualidad en las excavaciones arqueológicas del Castro de Vigo, yacimiento cuya cronología va del siglo III antes de Jesucristo al IV después de Jesucristo. Se analizará la cerámica indígena y romana, las monedas y los objetos de bronce, hierro, piedra y vidrio, que nos documentan, entre otras cosas, el importante comercio islámico romano con el litoral del Noroeste Peninsular, siendo el momento de mayor auge del mismo el siglo I después de Jesucristo.

Aux fouilles archéologiques effectuées au Castro à Vigo, gisement dont la chronologie va du III ${ }^{e}$ siècle avant $J$. C. au IVe siècle d. J. C., on présente les pièces les plus importantes trouvées jusqu'au présent. On analysera la céramique indigène et romaine, les monnaies et les objets en bronze, en fer, en pierre et en verre, qui nous renseignent entre autres sur l'important commerce atlantique romain avec le littoral du Nord-Est de la péninsule ayant atteint son apogée le siècle I. d. J. C.
\end{abstract}

\section{EL YACIMIENTO Y SUS EXCAVACIONES}

El Castro de Vigo está situado en pleno centro de la ciudad, en el conocido Monte del Castro (en la actualidad parque público) y se encuentra a 147 metros de altitud.

Sus coordenadas geográficas son: $08^{\circ} 43^{\prime} 30^{\prime}$, longitud occidental y $42^{\circ} 14^{\prime} 00^{\prime \prime}$ latitud septentrional. Corresponde a la hoja 223 del mapa topográfico del Instituto Geográfico Nacional, escala $1: 50.000$; y fotografía aérea $n .^{\circ} 13.345$, rollo 145 del vuelo nacional 1956-57 del Servicio Geográfico del Ejército, escala aproximada 1:30.000.

En 1952 y 1970 se van a realizar los primeros trabajos arqueológicos en la ladera Noroeste del yacimiento, dando como resultado el hallazgo de varias construcciones castreñas y la recogida de un abundante material arqueológico.

Desde 1981 hasta la actualidad, se van a reanudar las campañas arqueológicas en este poblado castreño, lográndose localizar más de cuarenta estruc- turas de diferente tipología y numerosos objetos arqueológicos (HIDALGO CUÑARRO 1981, 1983 y 1985a).

\section{LOS MATERIALES ARQUEOLÓGICOS}

A continuación vamos a analizar muy sintéticamente y de forma selectiva los materiales arqueológicos más importantes localizados en las diferentes campañas realizadas en este yacimiento. Para facilitar su estudio los hemos agrupado en los siguientes apartados: cerámica indígena, cerámica romana, monedas, bronce, hierro, piedra y vidrio.

\section{CERÁMICA INDÍGENA}

Aunque la forma cerámica más generalizada en este castro son las ollas de cuerpo globular, borde abierto y base plana, existen dos tipos de vasijas que 

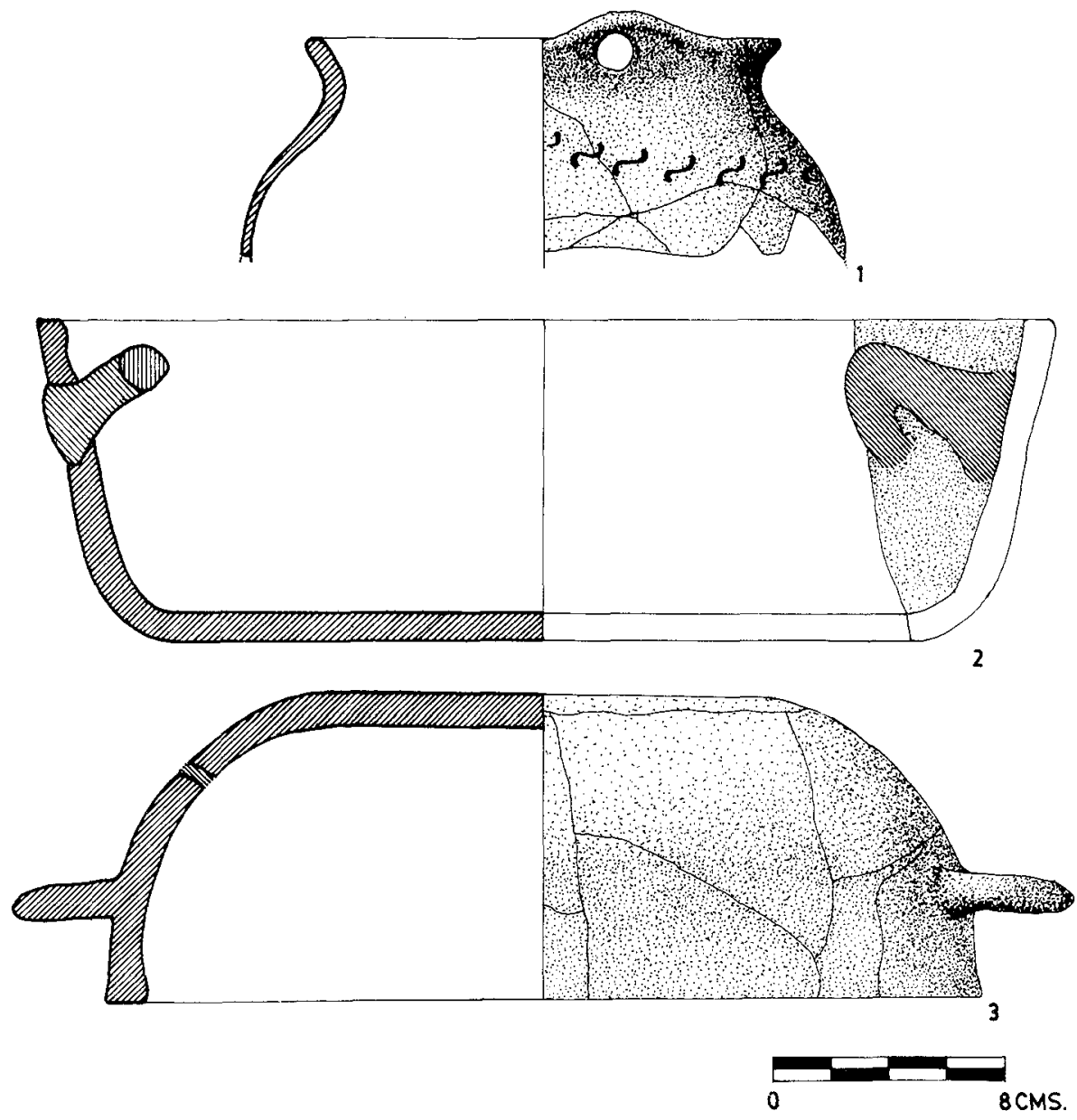

Fig. I.-Cerámica indígena de cocina: «Vasija de orejas» (1), «vasija de asas interiores» (2) y tapadera (3).

por su originalidad y bien conocida cronología es interesante señalar.

Uno de estos ejemplares son las vasijas de orejas (fig. I, 1), cuya característica fundamental (y que les da el nombre con el que son conocidas vulgarmente) es que poseen en la parte alta de su borde engrosado un orificio de suspensión. Se trata de una forma bien estudiada y que se fecha hacia mediados del siglo I antes de Jesucristo, llegando hasta época de Tiberio (FERREIRA DE ALMEIDA 1974a, 195 y ss.).

El otro modelo consiste en fuentes bajas conocidas como «vasijas de asas interiores» (fig. I, 2) por el detalle de poseer su sistema de prehensión y suspensión localizado en la parte interna del recipiente cerámico. Su cronología se sitúa en torno al siglo II-I antes de Jesucristo (FERREIRA DE ALMEI-
DA 1974a, 187, y 1974b, 27). Se conocen diversas variantes de este tipo, frecuentes en castros del Sur de la provincia de Pontevedra y Norte de Portugal (HIDALGO CUÑARRO y COSTAS GOBERNA 1979, 181 ss.).

Son muy interesantes unas formas de tapaderas, cóncavas y con asas horizontales, poco frecuentes en yacimientos de esta época (fig. I, 3).

En cuanto a las técnicas decorativas que se pueden documentar en este yacimiento, tenemos bien representadas la incisión, la impresión, la estampilla, la decoración plástica y la bruñida. En ocasiones, se emplean aisladamente y, en otros casos, combinadas (fig. II, 1). Los diseños ornamentales son todos geométricos. Abundan los círculos simples y concéntricos, los triángulos y rombos, los dientes de lobo o zig-zags, las acanaladuras, las ovas... 

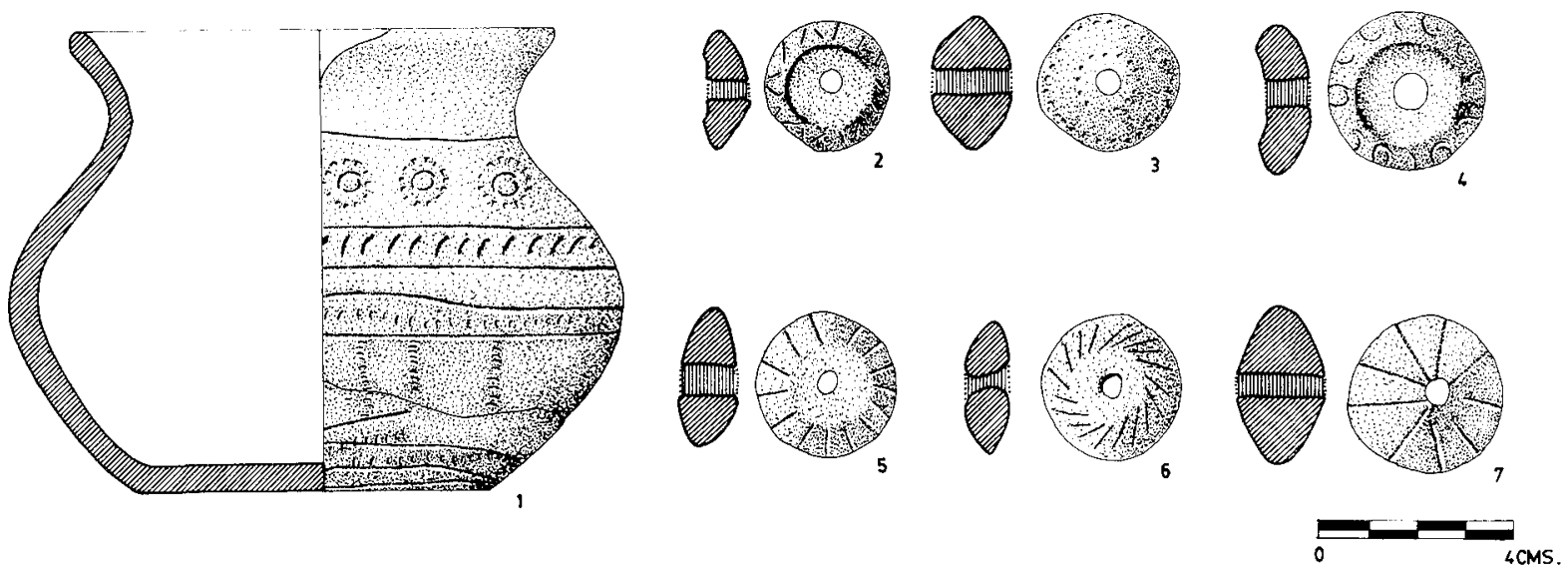

Fig. II .-Cerámica indígena decorada (1) y «fusayolas» (2-7).

Los motivos decorativos más frecuentes son los estampillados, y éstos, por paralelismos con otros yacimientos, podríamos datarlos entre los siglos II y I antes de Jesucristo (FERRERIA DE ALMEIDA, SOEIRO, BROCHADO DE ALMEIDA y BAPTISTA 1981, 45 y ss.).

Para finalizar este apartado dedicado a la cerámica indígena, hemos de mencionar la gran cantidad de fusayolas encontradas, que presentan diferentes pesos, diámetros, formas y decoraciones (fig. II, 2-7). Estas interesantes piezas cerámicas son objeto de numerosos estudios, que cuestionan, entre otros puntos, su origen y su función (CASTRO CUREL 1980, 127-146, y SALETE DA PONTE 1978, 133-146).

\section{LA CERÁMICA ROMANA}

Este tipo de cerámica es sin lugar a duda el más abundante en este yacimiento. Para su estudio podíamos hacer dos grandes grupos: cerámica fina $\mathrm{y}$ común.

\subsection{Cerámica fina}

De este tipo de vasijas tenemos representadas en el Castro de Vigo cerámicas campanienses, «terra sigillata» itálica y sudgálica, cerámica marmorata, «terra sigillata» hispánica, cerámica pintada y lucernas. A continuación pasamos a estudiar cada una de ellas.
Se recogieron varios fragmentos de cerámicas campanienses B y C (fig. III, 1), de formas indeterminadas y que generalmente se fechan desde mediados del siglo II hasta la mitad del siglo I antes de Jesucristo (LAMBOGLIA 1952, y MOREL 1981).

De «terra sigillata» itálica poseemos diversos fragmentos que podrían datarse hacia el primer tercio del siglo I antes de Jesucristo o unos cuantos años antes, pues recuerdan formas estudiadas por Goudineau y que el mencionado autor fecha en dicho período (GOUDINEAU 1976, 290 y ss.).

Tenemos de este tipo de cerámica (fig. III, 2) una marca incompleta de alfarero (C. MVR) que podría tratarse de C. MVRRIVS, alfarero de Arezzo (OXE 1968, 271-273).

De «terra sigillata» sudgálica tenemos varios fragmentos, tanto decorados como lisos. De los primeros podemos destacar uno decorado con un grifo alado rodeado de guirnaldas (fig. III, 3), cuyo paralelo más inmediato lo tenemos en Conímbriga (VARIOS, 1975, lám. XVIII, 35) y que podría datarse, por semejanza a otros, en época de Vespasiano (OSWALD 1964a, 69 y lám. XLII).

En formas lisas se documentan Drag. 27, 24/25, 18, $15 / 17$ y Ritt. 8 .

Finalmente (fig. III, 4) poseemos una marca de alfarero (ARIATI) que recuerda otras localizadas en Tongres y Saalburg (OXWALD 1964b, 23 y 61).

Se encontraron diferentes fragmentos de cerámica marmorata, pertenecientes a formas Drag. 15/17 y Ritt. 8 (fig. III, 5-7). Este tipo de cerámica no estaba documentada en nuestra área geográfica y es escasa en la Meseta (SÁNCHEZ PALENCIA 

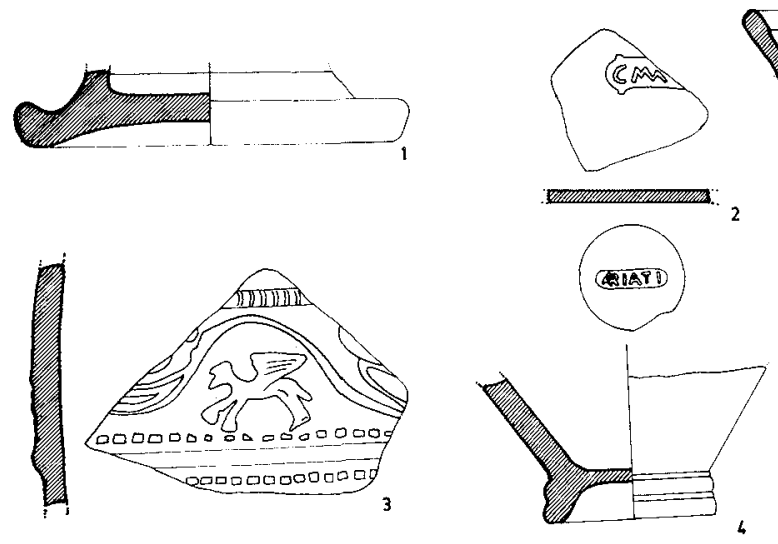
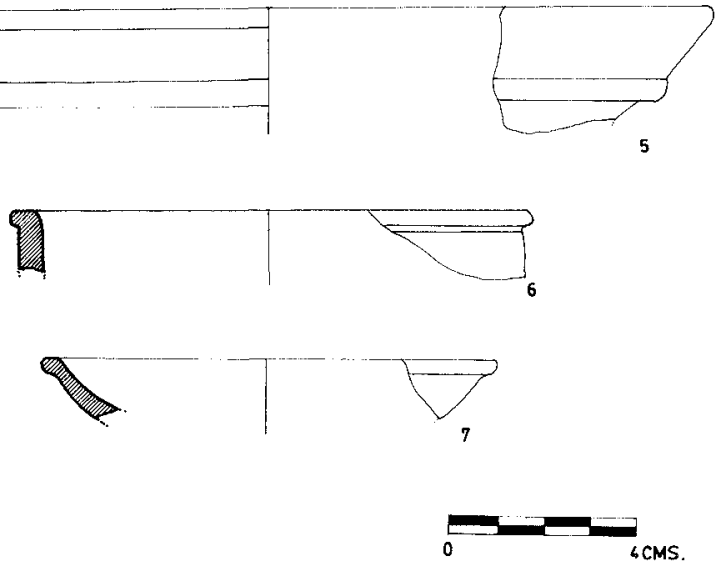

Fig. III.-Cerámica campaniense B (1), marca de alfarero en «terra sigillata» itálica (2), «terra sigillata» sudgálica decorada (3), marca de alfarero en «terra sigillata» sudgálica (4) y cerámica marmorata (5-7).

y FERNÁNDEZ POSSE 1985, 256, y MAÑANES 1983,152 y 214 , fig. 15 , números $1-3$ ). Sin embargo, ya aparece frecuentemente en Conímbriga (MOUTINHO DE ALARCÃO 1975, 70) y está muy bien documentada en las costas peninsulares desde el cabo de San Vicente al de Creus (BALIL 1982, 179-180). Esta cerámica se fecha en época claudioflavia, viéndose que empieza a disminuir desde Vespasiano (OXWALD y PRICE 1920, 175-180). Como se recordará, este tipo de cerámica es producida por el famoso taller gálico de la Graufesenque.

La «terra sigillata» hispánica es la cerámica fina más numerosa en este yacimiento.

De las formas decoradas destacaremos primeramente una Drag. 29, que presenta una escena de caza (ciervos y perros), completando dicho diseño motivos cruciformes y línea ondulantes (fig. IV, 1). Poseemos numerosos paralelismos para esta pieza (MEZQUIRIZ DE CATALÁN 1961, láms. 29, 5961 y 73-75; ROCA ROUMENS 1976, lám. 42, número 188; GARABITO y SOLOVERA 1976, fig. 7, y DELIBES DE CASTRO 1975, 162-163, fig. 43), que podemos fechar hacia el año 60/70 después de Jesucristo (MEZQUIRIZ DE CATALÁN 1961, 88-94).

Otro fragmento decorado con guirnaldas terminadas en hojas también nos sitúa (por paralelismos con otros modelos) hacia el 70 después de Jesucristo (GARABITO GÓMEZ 1978, 496) (fig. IV, 2).

Tenemos luego una forma Drag. 35 decorada con hojas de barbotina en el borde (fig. IV, 3) que se data ya hacia la primera mitad del siglo II, pero que perdura hasta finales del imperio (GARABITO
GÓMEZ 1978, 289, Y MEZQUIRIZ DE CATALÁN 1961, 63-66).

Por último, vemos una forma Drag. 37 con friso de círculos festoneados (fig. IV, 4), motivo este muy corriente en otros yacimientos.

Las formas lisas son muy variadas: Drag. 15/17, $18,24 / 25,27$ y Ritt. 8, entre otras. Algunas formas Drag. $24 / 25$ poseen decoración sencilla de ruedecilla (fig. V).

Poseemos cuatro marcas de alfarero en este tipo de cerámica. Tan sólo una de ellas está completa.

En esta última, se puede leer OF LVPIAN (fig. VI, 1); corresponde a una forma Drag. 27 y sus paralelismos más inmediatos los tenemos en Conímbriga (VARIOS, 1975, 206-207, lám. LIV), Mauritania Tingitana (BOUBÉ 1966, 115-143) y Sala (BOUBÉ 1968-1972, 119-126).

Las marcas incompletas son: OI..N.. en forma Drag. 15/17 (fig. VI, 2); ACV... en forma Drag. 27 (fig. VI, 3) y O ..ESTO en forma indeterminada (fig. VI, 4). La segunda de ellas (ACV...) posee numerosos paralelos: en la Península Ibérica (Tricio, Corella, Mérida, Itálica, Conímbriga...) y en Mauritania Tingitana (MEZQUIRIZ DE CATALÁN 1961, 45, lám. 8; GARABITO GÓMEZ 1978, 291-292; VARIOS, 1975, 7-8, y BOUBÉ 1968-1972, 119-126).

La cérámica pintada encontrada en el Castro de Vigo se trata (mayoritariamente) de vasijas de cuerpo globular y asas de sección elíptica que van desde el borde al hombro del recipiente. La decoración es geométrica, reproduciendo triángulos rayados y reticulados (fig. VI, 5). Podemos datar estas cerámicas como producciones altoimperiales y son frecuen- 

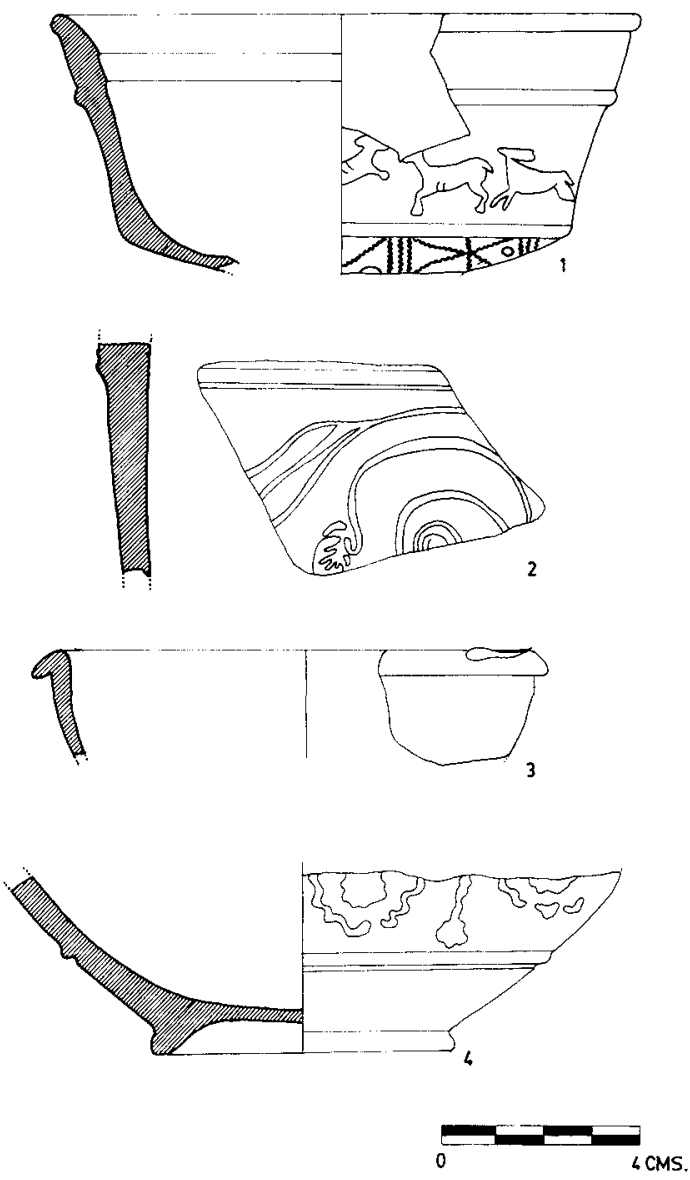

Fig. IV.—《Terra sigillata» hispánica decorada.

tes en yacimientos portugueses, como Conímbriga, Briteiros, Guifões y Monte Mozinho (ABASCAL PALAZÓN 1984, 198-199 y 201, fig. 4, n. ${ }^{\circ} 10$ ).

Finalmente, podemos decir que se recogieron diversos fragmentos de lucernas de volutas, que se suelen fechar en época julio-claudia, destacando una pieza que conserva una «nike» o diosa alada de la victoria (HEINZ MENZEL 1969, 42).

\subsection{Cerámica común}

Este tipo de cerámica se puede analizar muy sintéticamente, englobándola en tres grupos: de cocina, de mesa y para guardar y transportar provisiones. Mención aparte merecen las pesas de telar y algunas «tegulae» recogidas.

La cerámica de cocina nos muestra gran variedad de ollas con borde vuelto hacia afuera (algunas con ranura en el mismo, para ajuste de su tapa); cuencos con borde horizontal y con visera; platos de borde engrosado (fig. VII, 1); platos de borde bífido (fig. VII, 2); guentes de barniz interior rojopompeyano (fig. VII, 3); tacitas de cuerpo agallonado; morteros (fig. VII, 4-5) y tapaderas de diversos tipos.

La cerámica de mesa nos viene documentada sobre todo por recipientes de paredes finas de variada tipología (fig. VIII, 1-2) y por jarras.

De estas últimas, tenemos jarras de un asa con boca y cuello anchos, bocales de un asa con boca ancha y cuello poco marcado, jarras de boca ancha y pico y jarras con pico trilobulado. Destaca de todas ellas una que posee en la zona central de su cuerpo un «grafitti» que consiste en una rośácea de seis pétalos, inscrita en una circunferencia (fig. VIII, 3).

Esta cerámica común romana de cocina y mesa nos muestra modelos bien estudiados y cuya cronología va desde comienzos del siglo I hasta finales del III después de Jesucristo (VEGAS 1973; SANTROT 1979; TRUFFEAULIBRE 1980; ALARCÃO 1974, y BELTRÁN LLORIS 1978).

Son numerosos los yacimientos romanos en donde vemos este tipo de cerámica bien representada, con diversas variantes: Caesaraugusta (BELTRÁN LLORIS, AGUAROC, MOSTALAC y SÁNCHEZ, 1980); Pompaelo (MEZQUIRIZ DE CATALÁN 1978); Lacipo (PUERTAS TRICAS 1982); Cástulo (BLÁZQUEZ 1979, 240 y ss.); Complutum (FERNÁNDEZ-GALIANO 1984); Lancia (JORDÁ CERDÁ 1962); Tiermes (VARIOS, 1984); Cartuja (SERRANO RAMOS 1978, 243 y ss.); Portus Illicitanus (SÁNCHEZ FERNÁNDEZ 1983, 285 y ss.); Testar de Onda (IVES MONTMESSIN 1980, 243 y ss.); entre otros muchos que podíamos citar, ciñéndonos a la Península Ibérica.

De cerámica para guardar y transportar provisiones tenemos también numerosos ejemplares. De la primera, poseemos ollas de borde engrosado y vuelto hacia afuera y diversos tipos de dolios. En cuanto a ánforas, podemos decir que existen dos grandes grupos.

La gran mayoría corresponde a ánforas imperiales españolas (fig. IX, 1-2), que se englobarían en una extensa familia que denominaremos Dressel 10-24 y que sirvieron para traer hasta nuestras costas salsas de pescado de la Bética. Su cronología es amplia, abarcando los tres primeros siglos de nuestra era (BELTRÁN LLORIS 1970, 388 y ss.).

Tenemos, sin embargo, también algunos ejemplares del tipo Dressel I, con sus tres variantes A, 

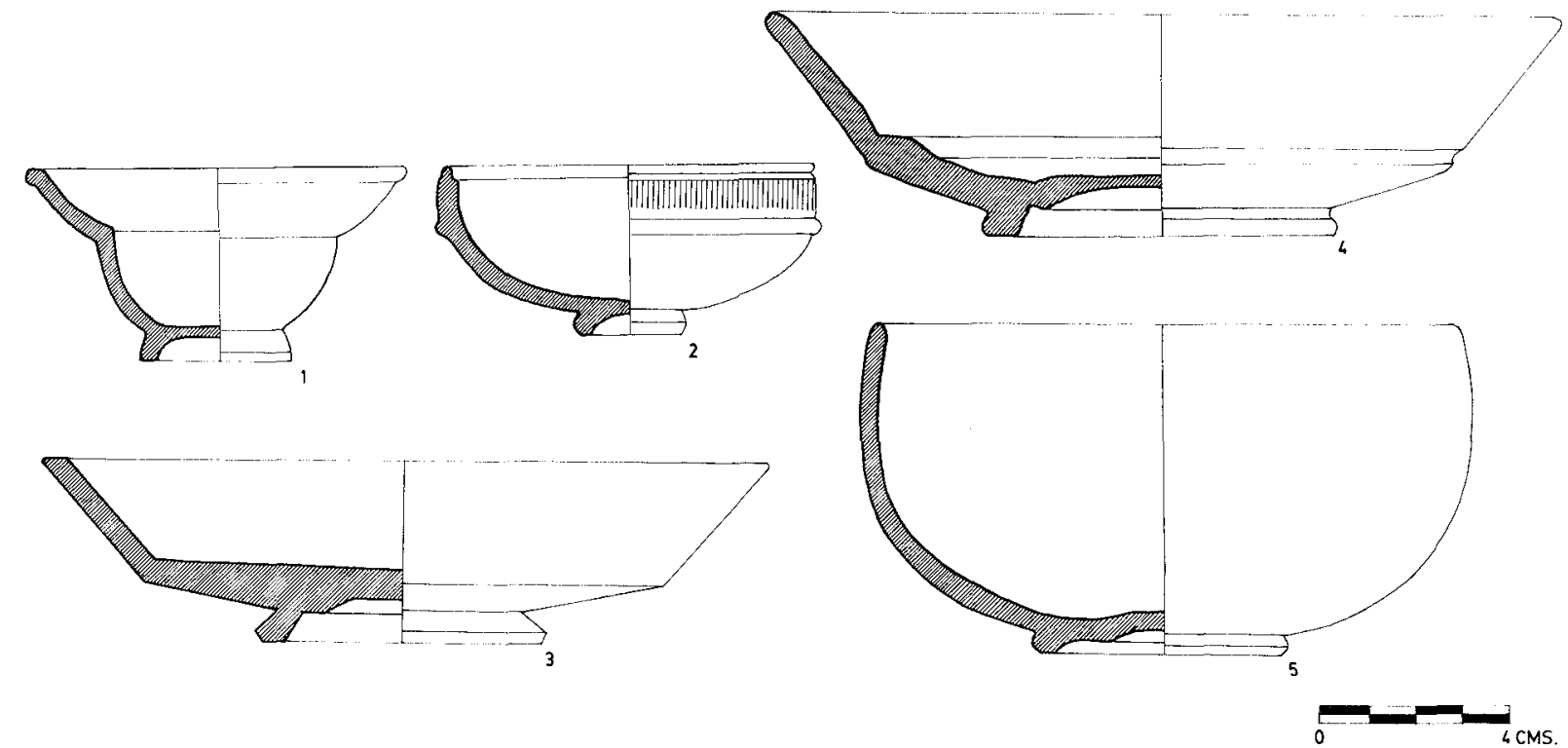

Fig. V.—《Terra sigillata» hispánica lisa.

B y C (fig. IX, 3-4), destinados al transporte de vinos itálicos y cuya cronología va desde el siglo II antes de Jesucristo hasta el tiempo de Augusto (LAMBOGLIA 1955, 241-270).

Poseemos dos marcas de alfarero: $\mathrm{L} \cdot \mathrm{HOR}$ (fig. IX, 5 ) y TSP (fig. IX, 6). Son muy abundantes los remates o puntas de ánfora que tienen «grafitti» de motivos geométricos o de letras mayúsculas.
Por último, podemos señalar que fueron muy numerosos los «pondus» o pesas de telar que se han localizado en este yacimiento, llegando a rebasar los cincuenta ejemplares. Existe una variada tipología que no se aparta de las ya conocidas en otros yacimientos (FATAS 1967, 203 y ss., por ejemplo).

Finalmente, para concluir este amplio apartado sobre la cerámica romana del Castro de Vigo, dire-
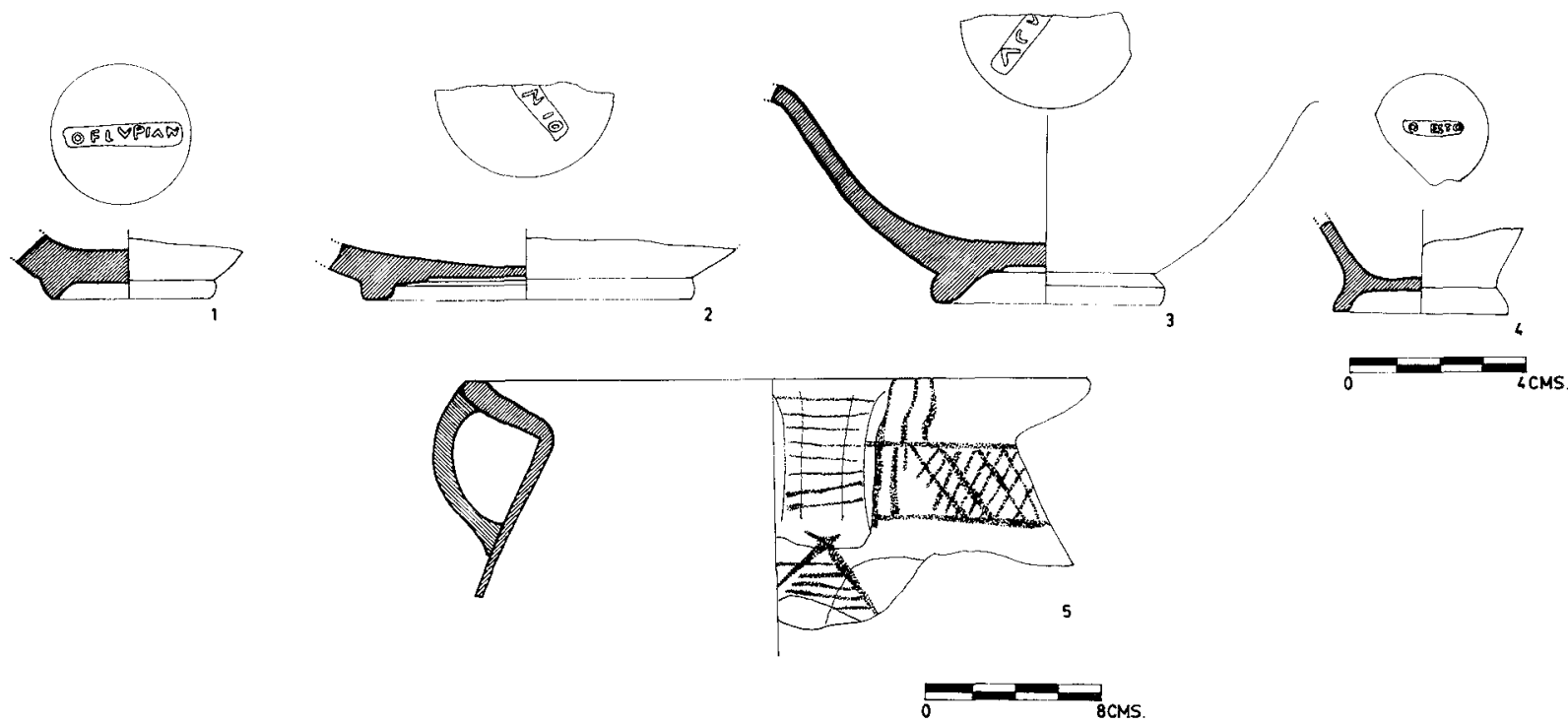

Fig. VI.-Marcas de alfarero en «terra sigillata» hispánica (1-4) y cerámica pintada (5). 

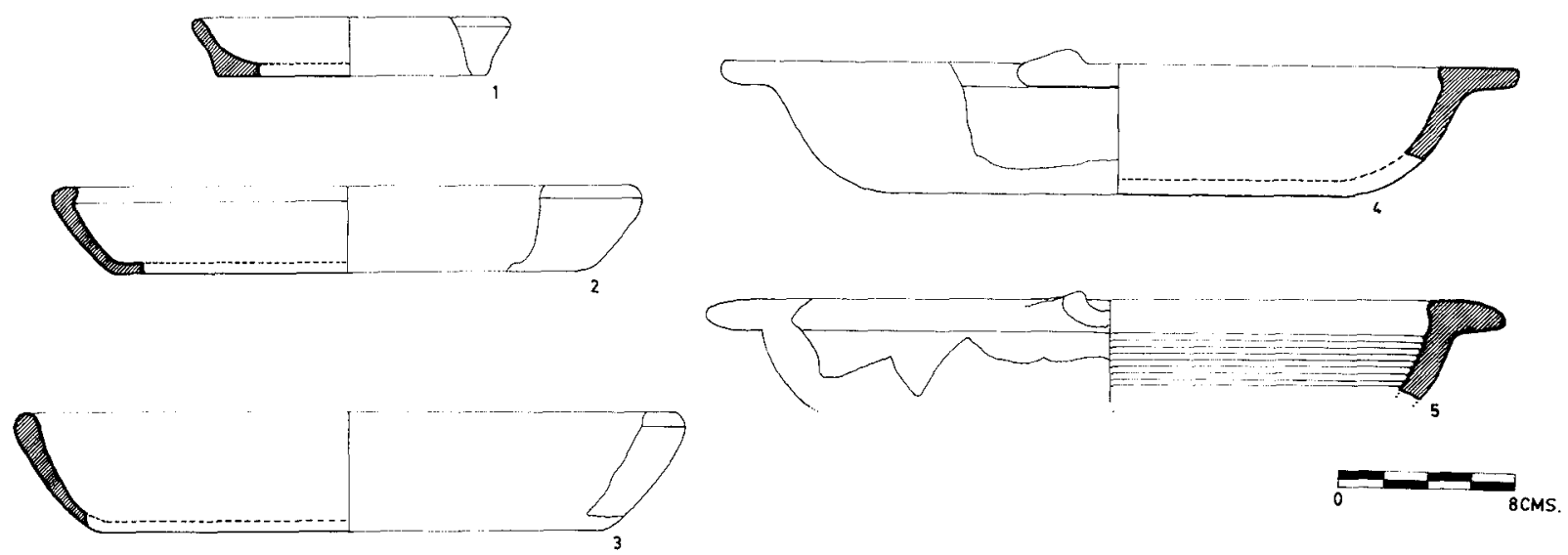

VII.-Cerámica común de cocina: Plato de borde engrosado (1), plato de borde bífido (2), fuente de barniz interior rojo-pompeyano (3) y morteros (4-5).

mos que se recogieron abundantes tégulas e ímbrices, destacando una tégula que posee en su zona central una gran perforación, posiblemente destinada a facilitar la salida del humo procedente del hogar del interior de la vivienda. El paralelo más cercano que hemos encontrado a esta peculiar pieza lo poseemos en Conímbriga y se fecha en período augusteo (MOUTINHO DE ALARCÃO y SALETE DA PONTE 1984, 240).

\section{LAS MONEDAS}

En las diferentes campañas arqueológicas realizadas en el Castro de Vigo se localizaron dos mo- nedas de plata y siete de bronce, bastante bien conservadas y que permiten su correcta identificación.

De las primeras tenemos un quinario de Octavio Augusto, cuya ceca de emisión fue Emerita Augusta y su fecha de acuñación se sitúa en torno al año 25 al 23 antes de Jesucristo (BELTRÁN MARTÍNEZ 1976, 95 y ss.). Y la otra es un denario de Vitelio que fechamos hacia el año 69 después de Jesucristo y cuyos paralelismos son muy conocidos (HAROLD MATTINGLY 1965, 372 y ss.).

De las monedas de bronce, mencionaremos primeramente una ibérica. Se trata de un as de patrón semiuncial reducido, cuya ceca de emisión fue $G a$ des y su acuñación podemos enmarcarla en un período entre el 45 antes de Jesucristo hasta la época de Claudio (GUADÁN 1980, 23, fig. 80).
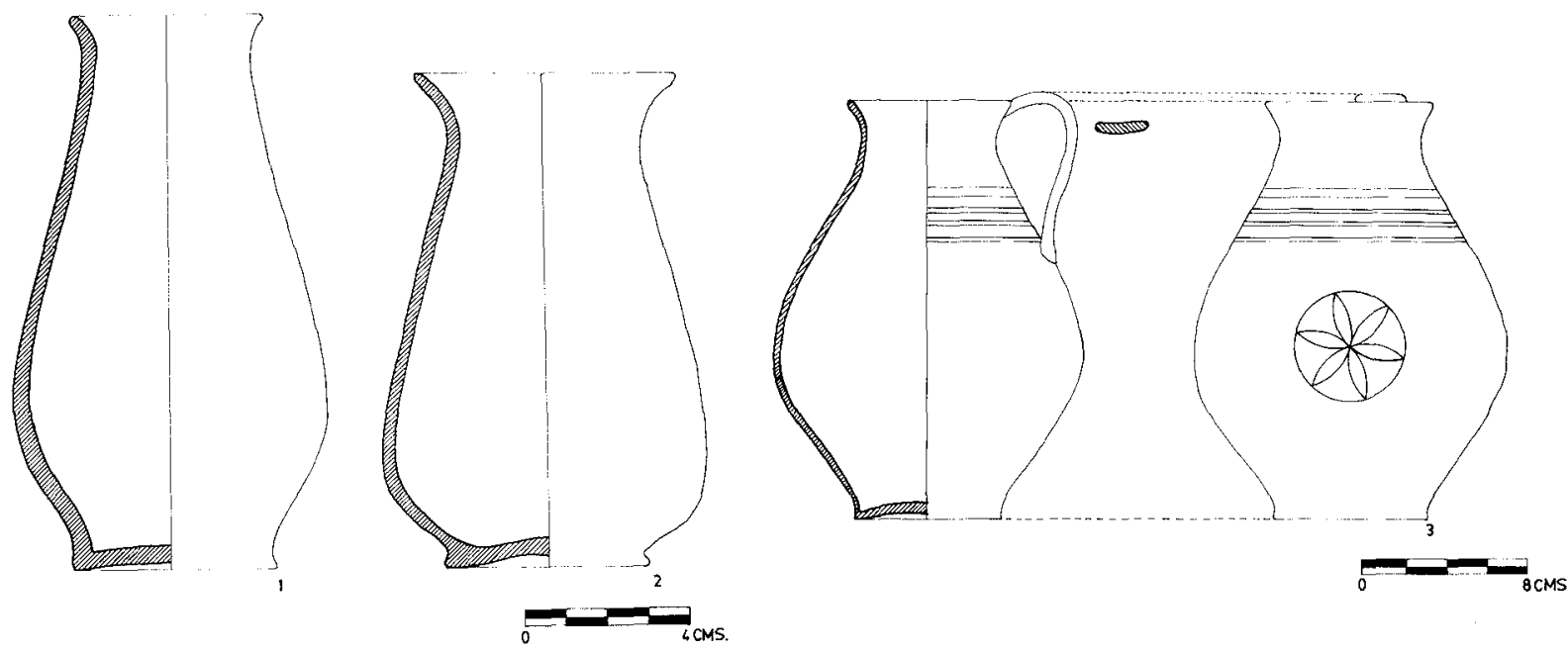

Fig. VIll.-Cerámica común de mesa: Recipientes de paredes finas (1-2) y jarra con «grafitti» (3). 

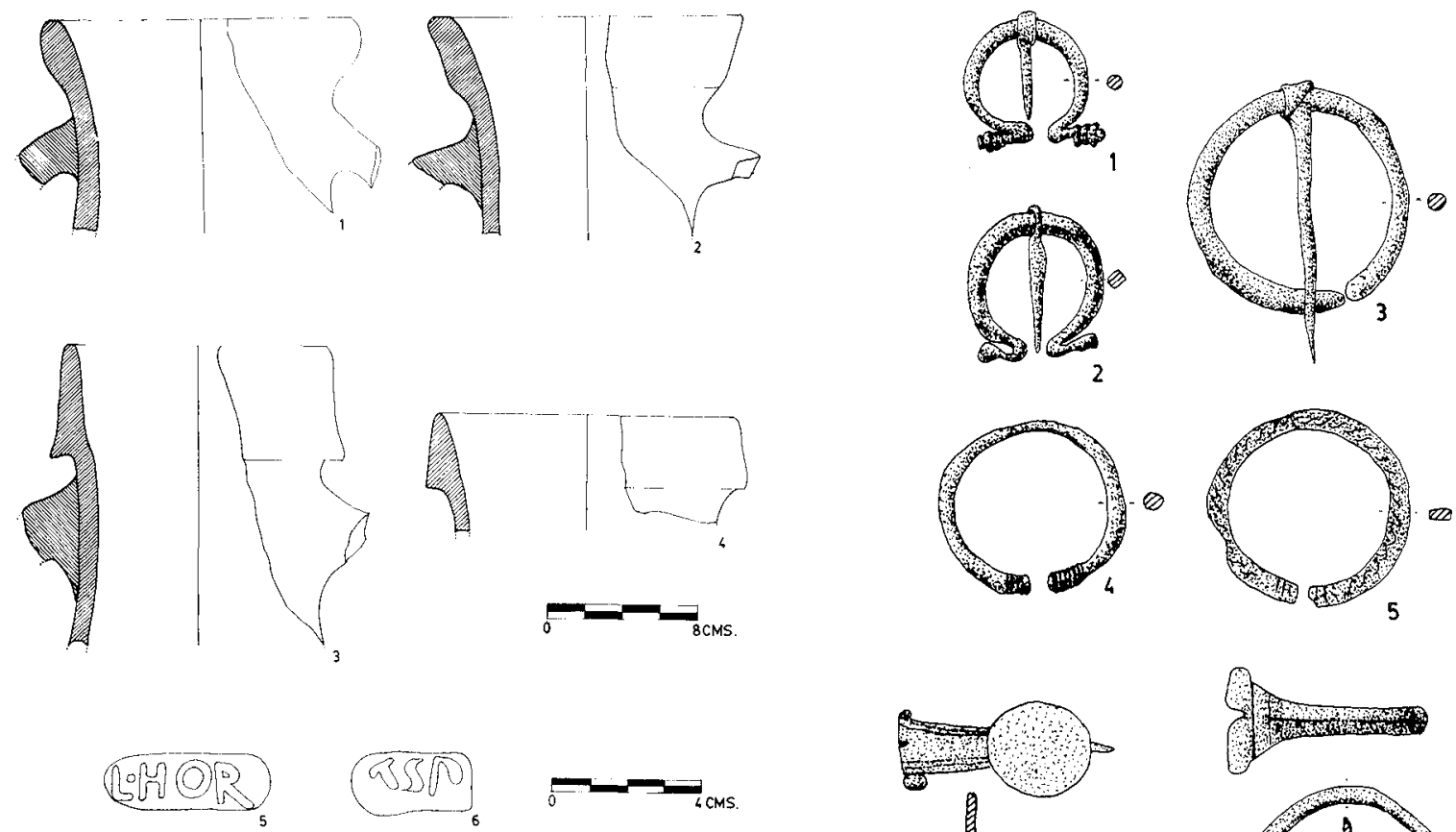

Fig. IX.—Ánforas imperiales (1-2), ánforas republicanas (3-4) y marcas de alfarero en ánforas (5-6).
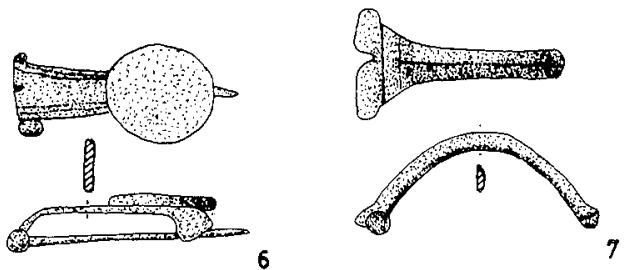

Tenemos luego, un sestercio de Agrippa, que podemos fecharlo entre el 39 al 27 antes de Jesucristo (SEABY 1981, 160, fig. 3).

Otra es un as de Octavio Augusto (27 antes de Jesucristo al 14 después de Jesucristo), cuya ceca de emisión fue la ciudad portuguesa de Évora (STEVENSON 1982, 354; SIMOES COELHO 1972, 45, y GIL FARRÉS 1966, 391 y 416). En otro as de Octavio Augusto vemos la «caetra» en su reverso, lo que nos permite fechar su emisión entre los años 27 al 23 antes de Jesucristo (CAAMAÑO GESTO 1979, 67-76).

Del emperador Adriano poseemos un sestercio y un as, de ceca incierta, pero cuya cronología se centra entre el 117-138 después de Jesucristo, siendo los paralelismos existentes muy numerosos (LAFUENTE 1877; BELTRÁN MARTÍNEZ 1950, 245 246; por ejemplo).

Finalmente, añadir que se localizó también un as de Trajano (98 al 117 después de Jesucristo).

\section{LOS OBJETOS DE BRONCE}

De este metal se encontraron numerosos objetos: fíbulas, alfileres de tocador, agujas, espátulas,
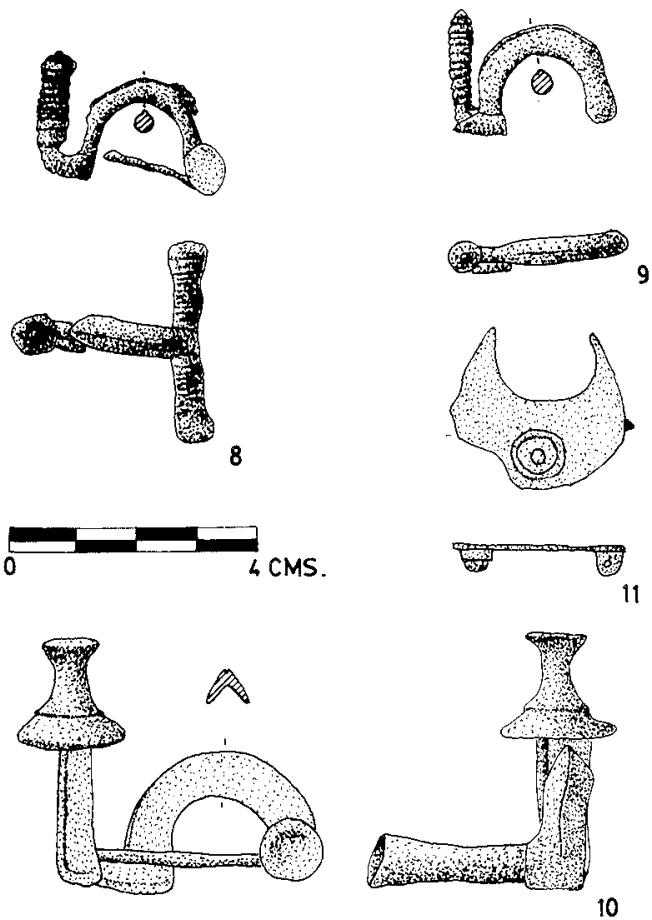

Fig. X.-Fíbulas: En omega (1-2), de aro interrumpido (3-5), de charnela y areo triangular (6-7), trasmontanas (8-9), de largo travesaño sin espira (10) y «lunulae» (11). 
cadenas de pequeñas dimensiones, clavos, apliques, cuentas de collar o pulsera, fragmentos de sítulas, colgantes... De todos ellos nos detendremos a analizar las diferentes fíbulas que se recogieron en este castro y que forman una variada tipología.

Las más abundantes son las conocidas como $f i$ bulas anulares romanas. Dentro de este tipo tenemos diversas «en omega» (fig. $X, 1-2$ ) y otras «de aro interrumpido» (fig. $X, 3-5$ ). Según diferentes autores, estas piezas poseen una cronología que en ocasiones no coinciden unos con otros. Así tenemos que si para Salete da Ponte se datan en los tres primeros siglos de nuestra era, según Ettlinger se pueden fechar aún hasta el siglo siguiente, mientras que para Jobst, por último, ya se dan en la segunda mitad del siglo II antes de Jesucristo y llegan tan sólo hasta la primera mitad del siglo III antes de Jesucristo (MARINÉ 1978, 372-394).

Tenemos luego varias fíbulas de charnela y arco triangular (fig. $\mathrm{X}, 6-7$ ), cuya cronología se centra hacia el cambio de Era, pues si bien se dan en el siglo I antes de Jesucristo, son más frecuentes en el siglo I después de Jesucristo (SALETE DA PONTE 1973, 182; 1979, 197, y 1982, 157).

También poseemos diversas fíbulas de las denominadas trasmontanas (fig. $X, 8-9$ ), que se fechan en torno a los siglos III-II antes de Jesucristo (SALETE DA PONTE 1980, 111-115).

Otro tipo de fíbula presente en este yacimiento es la conocida como de largo travesaño sin espira (fig. X, 10). Su cronología se sitúa alrededor del siglo III al I antes de Jesucristo (FARIÑA BUSTO 1979, 28 y ss.).

Por último, poseemos un interesante ejemplar, que corresponde al tipo 41 de Ettlinger y que denomina lunulae (fig. $\mathrm{X}, 11$ ) por la forma que tiene. Para la mencionada autora se puede datar entre el año 20 y el 50 después de Jesucristo (ETTLINGER 1973, 29 y 113, lám. 12, núms. 18 y 19).

\section{LOS OBJETOS DE HIERRO}

En las diferentes campañas que se llevaron a cabo en este yacimiento se localizaron diversos objetos de hierro, siendo muy abundantes los clavos (de diferente tipología), los arcos o argollas y las láminas o placas. Sin embargo, se encontraron algunas piezas que, por su interés, analizaremos a continuación.
Así tenemos un cuchillo de hoja curva (fig. XI, 1) que posee dos pequeños agujeros en su espigo para facilitar el enmangue de su empuñadura de madera, cuyos paralelos tipológicos más próximos nos dan una cronología que nos acerca en torno al siglo IV-III antes de Jesucristo (CERDEÑO SERRANO $1979,56,59-60,67-68$ y 74; figs. 3, núms. 2, 3, y 4, y 4, núm. 6, y FERNÁNDEZ-GALIANO 1976, 60 , fig. 1 , núms. 2-4).

Poseemos también varias puntas de jabalina (fig. $\mathrm{XI}, 2-4)$ y lanza (fig. XI, 5), muy frecuentes en yacimientos de la Meseta (CERDEÑO SERRANO 1981,195 y ss.).

Finalmente destacar un fragmento de sierra (fig. XI, 6) bastante bien conservado, que podemos fechar en época de Adriano, habiéndose encontrado piezas similares en Portugal y Cataluña (SALETE DA PONTE 1974, 4 y ss., y SANAHUJA YLL 1971, 62 y ss. y fig. 18, núm. 1).

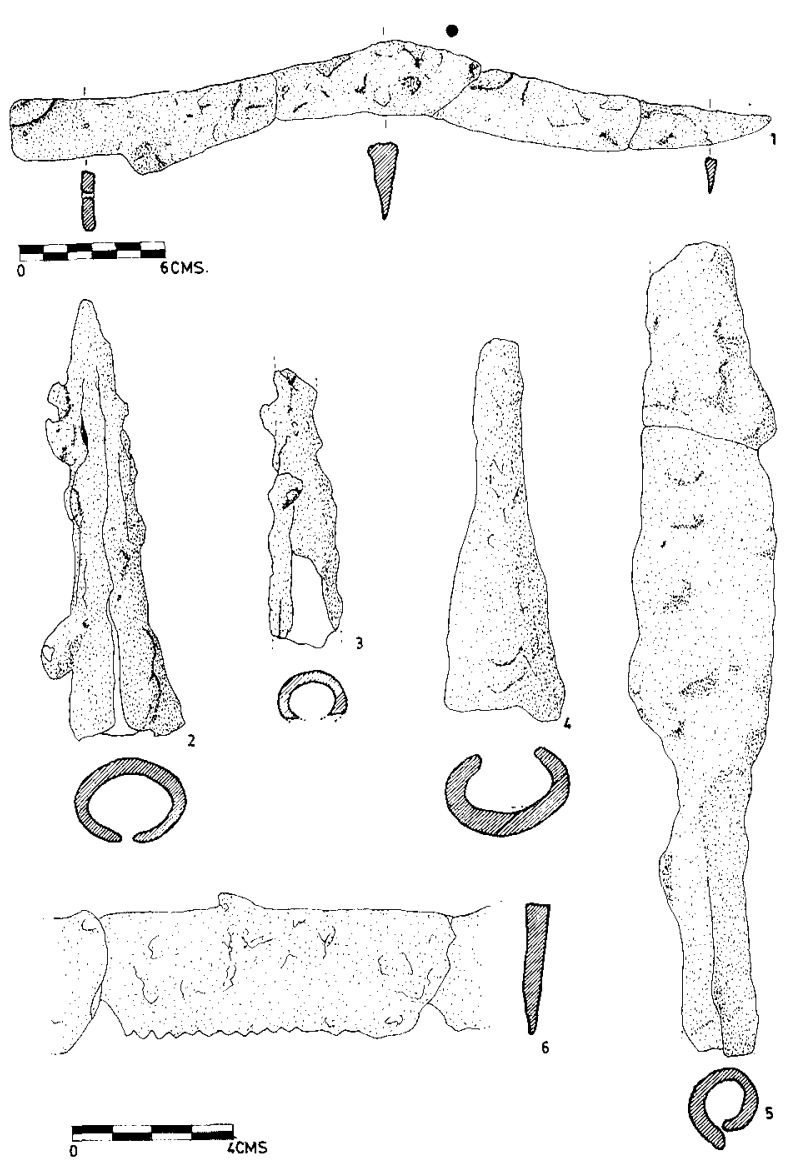

Fig. XI._Objetos de hierros: Cuchillo de hoja curva (1), punta de jabalina (2-4), punta de lanza (5) y sierra (6). 


\section{LOS OBJETOS DE PIEDRA}

Sin lugar a dudas, fueron los molinos circulares de mano los que en mayor número se recogieron dentro de este apartado (alrededor de treinta). Este tipo de piezas presenta diversas variantes y su uso está muy bien estudiado (CORREIRA BORGES 1978, 113-132). También se recogieron abundantes piedras de afilar y alisar, así como pesos de pesca o «poutadas».

Destaca un entalle en ágata que reproduce al tema de una cuádriga con su auriga y que fechamos hacia mediados del siglo I después de Jesucristo.

Por último, mencionar el hallazgo de diversas hachas pulimentadas (fig. XII), que presentan una variada gama de formas y tamaños. La aparición de estas piezas en castros llama la atención y actualmente se cuestiona su función y la cronología de las mismas (DE BLAS y MAYA 1974, 5 y ss., y FÁBREGAS VALCARCE 1981, 27-38).

\section{LOS OBJETOS DE VIDRIO}

De este tipo de objetos poseemos: fichas de juego, cuencos de costillas y cuentas de collar o pulsera.

Las fichas de juego o «tessalae» hasta ahora aparecidas son cuentas semiesféricas de color blanquecino y azul. Se suelen localizar frecuentemente en castros ya romanizados (FERREIRA DE ALMEIDA 1977,16 y 37).

Se recogieron numerosos fragmentos de cuencos de costillas de diferentes tonalidades: azul, verde, amarillo y blanco. Este modelo de recipiente de vidrio se data generalmente en todo el siglo I después de Jesucristo (VIGIL PASCUAL 1969, 103 y ss).

Finalmente, tenemos diversas cuentas de collar o pulsera, de diferentes dimensiones, formas y colores, muy corrientes en castros con claros influjos romanos (CARDOZO 1976, 53 y ss., y MARTÍNEZ TAMUXE 1983, 103; etc.).

\section{CONCLUSIONES}

Por las excavaciones arqueológicas realizadas hasta la actulidad en la ladera Noroeste del Castro de Vigo, teniendo en cuenta las secuencias estratigráficas establecidas, así como los materiales que identifican cada una de ellas, podemos señalar tres niveles de ocupación (HIDALGO CUÑARRO 1985 b , 523-533), que nuevas campañas pueden am-

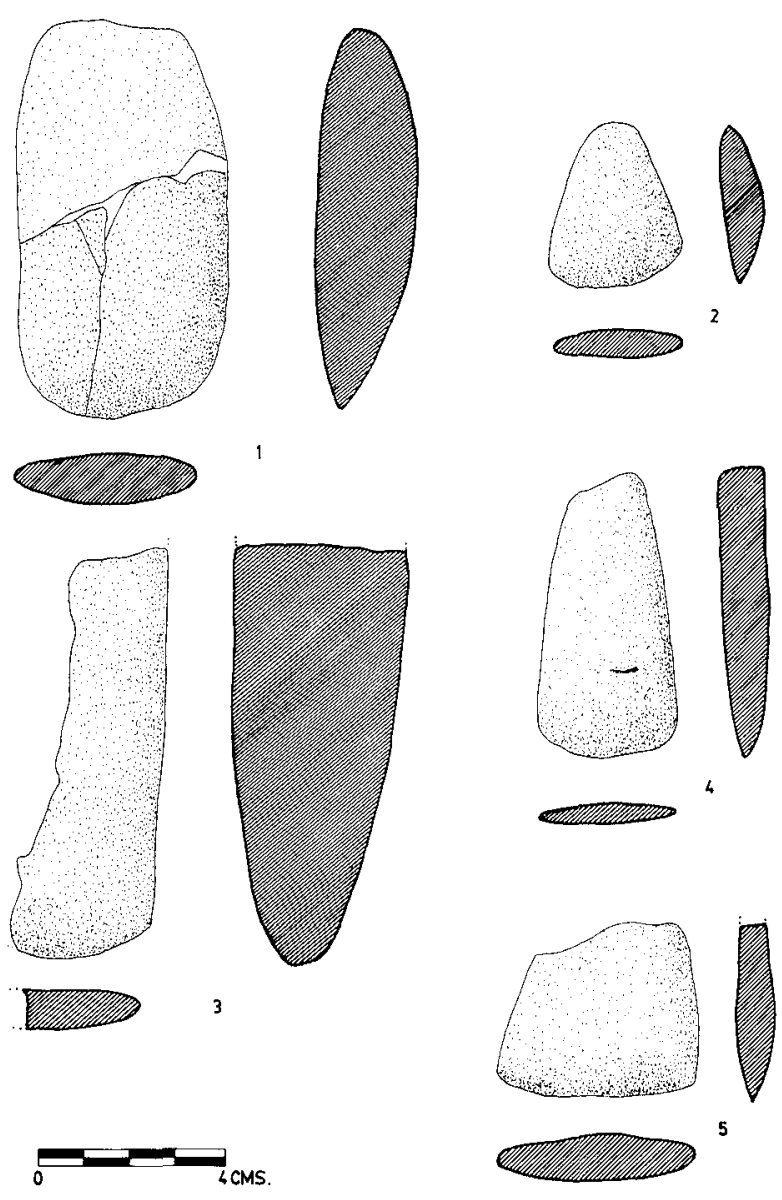

Fig. XII.-Hachas de piedra pulimentadas.

pliar y concretar más en algunos aspectos. Estos niveles o momentos de ocupación detectados, cronológicamente se sitúan de la siguiente forma:

Nivel I: Desde finales del siglo III o comienzos del siguiente hasta el último tercio del siglo I antes de Jesucristo.

Nivel II: su inicio se colocaría hacia finales del siglo I antes de Jesucristo, comprendería todo el siglo I después de Jesucristo y alcanzaría la mitad del siglo siguiente. Posiblemente en un futuro próximo se podrá dividir esta fase en dos períodos diferentes.

Nivel III: Iría desde mediados del siglo II después de Jesucristo y llegaría hasta el siglo IV.

El momento de mayor auge que posee este poblado podemos centrarlo durante todo el siglo I después de Jesucristo e incluso pudiera llegar hasta mediados del siglo siguiente. En esta fase se documenta perfectamente un importante comercio de importación, que ya se había iniciado nítidamente en una 
etapa anterior. Este comercio sería de productos manufacturados de lujo (como cerámica y vidrio, por ejemplo) y provisiones (aceite, vino y salsas de pescado), realizándose mayoritariamente por vía maritima.

Este comercio atlántico romano relacionará el Castro de Vigo en particular y los castros del Noroeste peninsular en general con el centro de Italia, el Sur de Francia y diversos núcleos de la Península Ibérica (HIDALGO CUÑARRO 1984, 371-387).

Para finalizar, podemos decir que las excavaciones arqueológicas del Castro de Vigo están permitiendo estudiar en profundidad y de forma detallada la importante fase de contacto del mundo indígena y el romano, que será un período decisivo para conocer las características que definen la evolución de la cultura castreña a la sociedad galaico-romana.

\section{BIBLIOGRAFÍA}

ABASCAL PALAZÓN, Juan Manuel. 1984:«La cerámica pintada de época romana en Portugal y sus conexiones periféricas». Revista de Guimaräes, XCIV.

ALARCÃO, Jorge de. 1974: Cerámica común local e regional de Conimbriga. Coimbra.

BALIL, Alberto. 1982: «Notas de cerámica romana (III)» Boletín del Seminario de Arte y Arqueología de la Universidad de Valladolid XLVIII.

BELTRÁN LLORIS, Miguel. 1970: Las ánforas romanas en España. Zaragoza.

- 1978: Cerámica romana. Tipología y clasificación. Zaragoza.

BELTRÁN LLORIS, AGUAROD, MOSTALAC y SÁNCHEZ. 1980: Caesaraugusta. I. Campaña 1975-76. Excavaciones Arqueológicas en España, 108.

BELTRÁN MARTÍNEZ, A. 1950: Curso de Numismática Antigua. Zaragoza.

- 1976: «Las monedas romanas de Mérida: su interpretación histórica». Augusta Emerita. Actas del Bimilenario de Mérida. Madrid.

BLÁZQUEZ, José María. 1979: Castulo II. Excavaciones Arqueológicas en España 105.

BOUBÉ, J. 1966: «La terra sigillata hispánique en Mauritanie Tingitane: suplement au catálogue des marques de potiers». Bulettin d'Archéologie Marocaine VI.

- 1968-1972: «Index des marques de potiers hispaniques trouvées a Sala». Bulletin d'Archéologie Marocaine VIII.

CAAMAÑO GESTO, José Manuel. 1979: «Aportaciones al estudio de las monedas de la caetra: Las monedas de la colección Blanco Cicerón (La Coruña)». Boletín Auriense IX.

CARDOZO, Mario. 1976: Citania de Briteiros e castro de Sabroso. Guimarães.

CASTRO CUREL, Zaida. 1980: «Fusayolas ibéricas: antecedentes y empleo». Cypsela III.

CERDENTO SERRANO, M. ${ }^{2}$ Luisa. 1979: «La necrópolis céltica de Sigüenza (Guadalajara)» Revista Wal-al-Hayara 6.

- 1981: «Sigüenza: enterramientos tumulares de la Meseta Oriental». Noticiario Arqueológico Hispánico 11.
CORREIRA BORGES, Nelson. 1978: «Mos manuais de Conínbriga». Revista Conimbriga XVII.

DE BLAS, M. A., y MAYA, J. L. 1974: «Hachas pulimentadas en castros asturianos». Boletín del Instituto de Estudios Asturianos LXXXI.

DELIBES DE CASTRO, Germán. 1975: «Colección arqueológica D. Eugenio Merino de Tierra de Campos-León». Revista del Centro de Estudios e Investigación S. Isidro I.

ETTLINGER, Elisabeth. 1973: Die römischen Fibel in der Schweiz. Bern.

FÁBREGAS VALCARCE, Ramón. 1981: «Os machados puimentados da colección La Iglesia». Revista Brigantium 2.

FARIÑA BUSTO, Francisco. 1979: "As fíbulas de longo travessão sem espira nos castros do NW peninsular». Boletín Auriense IX.

FATAS, G. 1967: «La colección de pesas del Museo Arqueológico de Zaragoza». Revista Caesaraugusta 29-30.

FERNÁNDEZ-GALIANO, Dimas. 1976: «Descubrimiento de una necrópolis celtibérica en Sigüenza (Guadalajara)». $R e$ vista Wad-Al-Hayara 3.

- 1984: Complutum. I. Excavaciones. Excavaciones Arqueológicas en España, 137.

FERREIRA DE ALMEIDA, Carlos Alberto. 1974a: «Cerámica castreja». Revista de Guimarães LXXXIV.

- 1974b: Escavações no Monte Mozinho. Peñafiel.

- 1977: Escavações no Monte Mozinho. Peñafiel.

FERRERIA DE ALMEIDA, C. A.; SOEIRO, T., BROCHADO DE ALMEIDA, C. A., y BAPTISTA, A. J. 1981: Escavações arqueológicas em Santo Estêvao de Facha. Ponte de Lima.

GARABITO GÓMEZ, T. 1978: Los alfares romanos riojanos. Producción y comercialización. Instituto Español de Prehistoria.

GARABITO, T., y SOLOVERA, M. ${ }^{a}$. 1976: «Terra sigillata de Tricio. III. Formas decoradas». Revista Studia Archaeologica 43.

GIL FARRÉS, O. 1966: La moneda hispánica en la Edad Antigua. Madrid.

GOUDINEAU, G. 1976: La céramique aretine lisse. París.

GUADÁN, A. M. 1980: La moneda ibérica. Madrid.

HAROLD MATTINGY, M. A. 1965: Coins of the roman Empire in British Museum. London.

HEINZ MENZEL. 1969: Antike Lampen. Mainz.

HIDALGO CUÑARRO, José Manuel. 1981: «El Castro de Vigo. Noticia preliminar de las excavaciones arqueológicas de $1981 »$. Revista del Museo Municipal «Quiñones de León» de Vigo 5.

- 1983: «Excavaciones arqueológicas en el Castro de Vigo». Revista del Museo Municipal «Quiñones de León» de Vigo 6.

- 1984: «El Castro de Vigo y el comercio atlántico romano en el Noroeste peninsular». Revista de Guimarães XCIV.

- 1985a: «Castro de Vigo. Campaña de 1983». Serie Arqueoloxía/Memorias da Xunta de Galicia 1.

- 1985b: «Excavaciones arqueológicas en el Castro de Vigo (Pontevedra)». Actas del XVII Congreso Nacional de Arqueologia, Logroño.

HIDALGO CUÑARRO, José Manuel, y COSTAS GOBERNA, F. J. 1979: «El castro "A Cidade" de Caneiro, Fozara (Ponteáreas)». Revista El Museo de Pontevedra XXXIII.

IVES MONTMESIN. 1980: «Description analytique de la céramique commune de Testar de Onda/Mas de Pere (Castellón)». Cuadernos de Prehistoria y Arqueología Castellonenses 7.

JORDÁ CERDÁ, Francisco. 1962: Lancia. Excavaciones Arqueológicas en España, 1. 
LAFUENTE, M. 1877: Historia General de España. Barcelona.

LAMBOGLIA, Nino. 1952: Per una clasificazione preliminare della cerámica campana. Bordighera.

- 1955: «Sulla cronologia delle anfore romane di eta republicana (II-I século a. C.)» Revista di Studi Liguri 3-4.

MAÑANES, Tomás. 1983: Astorga romana y su entorno. Valladolid.

MARINÉ, María. 1978: «Las fíbulas romanas del cerro Villar (Monreal de Ariza, Zaragoza)». Trabajos de Prehistoria 35.

MARTÍNEZ TAMUXE, X. 1983: Citania y Museo Arqueológico de Santa Tecla. A Guardia, Pontevedra.

MEZQUIRIZ DE CATALÁN, María Ángeles. 1961: Terra sigillata hispánica. Valencia.

- 1978: Pompaelo II. Pamplona.

MOREL, Jean-Paul. 1981: Cerámica campaniense: les formes. Roma.

MOUTINHO DE ALARCÃO, A. 1975: «Les sigillées sudgálliques». Conimbriga, $I V$, París.

MOUTINHO DE ALARCÃO y SALETE DA PONTE. 1984: Coleccôes do Museu Monográfico de Conimbriga. Coimbra.

OXE, A. 1968: Corpus Vasorum Aretinorum. Howard Comfort.

OXWALD, Félix. 1964 a: Index of figures types on terra sigillata. London.

- 1964b: Index of Potters Stamps on terra sigillata. London.

OXWALD, F. y PRYCE, T. 1920: An introduction to the studies of terra sigillata treated from a chronological atendpoint. London.

PUERTAS TRICAS. 1982: Excavaciones arqueológicas en Lacipo (Casares, Málaga). Campañas de 1975 y 1976. Excavaciones Arqueológicas en España, 125.

ROCA ROUMENS, M. ${ }^{a}$ Ángeles. 1976: Sigillata Hispánica producida en Andújar. Jaén.

SALETE DA PONTE. 1973: «Fíbula pre-rromanas e romanas de Conimbriga», Revista Conimbriga, XII.
- 1974: «Ferramentas para trabalhar a madeira». Revista Conimbriga XIII.

- 1978: «Instrumentos de fiacão, tecelagem e costua en Conimbriga». Revista Conimbriga XVII.

- 1979: «As fíbulas de Mirobriga». Revista Setuibal Arqueológica $\mathrm{V}$.

- 1980: «A génese das fíbulas do Noroeste Peninsular». Actas do I Seminario de Arqueoloxía do Noroeste Peninsular II.

- 1982: «As fíbulas do Museu Municipal de Figueira da Foz». Revista Conimbriga XXI.

SANAHUJA YLL, M. ${ }^{a}$ Encarna. 1971: «Intrumental de hierro $e$ industrial de la época ibero-romana en Cataluña». Revista Pyrenae 7.

SÁNCHEZ FERNÁNDEZ, M. ' José. 1983: «Cerámica común romana del Portus Illicitanus». Revista Lucentum II.

SÁNCHEZ PALENCIA, F. J., y FERNÁNDEZ POSSE, M. ${ }^{a}$ D. 1985: La Corona y el Castro de Corporales. I. Truchas (León). Campañas de 1978 a 1981. Excavaciones Arqueológicas en España, 141.

SANTROT, Marie-Helene et Jacques. 1979: Céramiques communes gallo-romaines d'Aquitania. París.

SEABY. 1981: Roman Silver Coins. London.

SERRANO RAMOS, E. 1978: «Cerámica común del alfar de Cartuja (Granada)». Revista Baetica 1.

SIMÕES COELHO. 1972: Numaria de Lusitania. Lisboa.

STEVENSON, S. 1982: A Dictionary of Roman Coins. London.

TRUFFREAU-LIBRE. 1980: La céramique commune galloromaine dans le Nord de la France. Lille.

VARIOS. 1975: Les sigilleés. Fouilles de Conimbriga, IV, París.

- 1984: Tiermes II. Excavaciones Arqueológicas en Espa$\tilde{n} a, 128$.

VEGAS, Mercedes. 1973: Cerámica común romana del Mediterráneo Occidental. Barcelona.

VIGIL PASCUAL, M. 1969: El vidrio en el mundo antiguo. Madrid. 